\title{
Conventional rotator cuff repair complemented by the aid of mononuclear autologous stem cells
}

\author{
João L. Ellera Gomes • Ricardo Canquerini da Silva • \\ Lúcia M. R. Silla • Marcelo R. Abreu • \\ Roberto Pellanda
}

Received: 9 February 2011 / Accepted: 1 July 2011 / Published online: 20 July 2011

(C) The Author(s) 2011. This article is published with open access at Springerlink.com

\begin{abstract}
Purpose To investigate the behavior of rotator cuff tears treated with conventional repair technique with the aid of autologous bone marrow mononuclear cells (BMMC).

Methods Fourteen consecutive patients (9 women, 5 men, mean age of 59.2 years) with complete rotator cuff tears (mean preoperative UCLA score of $12 \pm 3.0$ ) were fixed by transosseous stitches through mini-open incision, with subsequent injection of BMMC into the tendon borders, obtained from the iliac crest just prior to surgery. Magnetic resonance images (MRI) were acquired before and after surgery and evaluated by two musculoskeletal radiologists regarding new postoperative findings of patients treated with BMMC.

Results After a minimum 12-month follow-up period, the UCLA score increased from $12 \pm 3.0$ to $31 \pm 3.2$. Clinical findings remained unaltered in the following year in all but one patient (13/14). MRI analysis after a 12-month follow-up period demonstrated tendon integrity in all cases (14/14), presence of low-signal intensity areas along the supraspinatus
\end{abstract}

\footnotetext{
J. L. Ellera Gomes · L. M. R. Silla · R. Pellanda Faculdade de Medicina, Universidade Federal do Rio Grande do Sul (UFRGS), Porto Alegre, Brazil

J. L. Ellera Gomes - R. C. da Silva - L. M. R. Silla

R. Pellanda

Hospital de Clínicas de Porto Alegre (HCPA),

Porto Alegre, Brazil

M. R. Abreu

Hospital Mãe de Deus, Porto Alegre, Brazil

J. L. Ellera Gomes ( $\square)$

Rua Des. Moreno Loureiro Lima 195/901,

Porto Alegre, RS 90450-130, Brazil

e-mail: joelgo.voy@terra.com.br
}

tendon and distal muscle belly in 8 cases (8/14), and highintensity blooming small round artifact at the bursal and tendon topography in 11 cases (11/14). Six patients (6/14) showed formation of a high-signal intensity zone at the critical zone. Clinical findings remained unaltered in the following year in all but one patient, who relapsed into loss of strength and pain, being considered a bad result.

Conclusion Implantation of BMMC in rotator cuff sutures appears to be a safe and promising alternative to other biological approaches currently used to enhance tissue quality in affected tendons.

Level of evidence IV.

Keywords Rotator cuff - Bone marrow mononuclear cells

\section{Introduction}

The first repair of rotator cuff injury is attributed to Codman in 1911 [8]. However, little has changed in the philosophy of treatment since Neer, in 1972, who proposed simultaneous subacromial decompression by means of osteotomy of the acromion and suture of injured tendons [33].

The introduction of anchors [17] has facilitated tendon reintegration near the bone, while synthetic non-absorbable suture significantly increased its resistance [1]. With the advent of arthroscopy, these procedures became increasingly popular and widespread in the orthopedic community, but none of these advances has brought significant improvement to the quality of postoperative results in patients with large rotator cuff injuries: the overall rate of rerupture over the first postoperative year ranges from 25 to $65 \%$ depending on lesion extent $[15,22]$. 
Rotator cuff injuries are more common after the fourth decade of life [33], and in the majority of cases, they are caused by tendon avascular degeneration [36], which is also responsible for the high rate of postoperative retear. A strategy aiming to revitalize the tendon structure through cell therapy $[6,20,21]$ is the natural step ahead sought by many centers worldwide, once it would probably overcome this complication by increasing tendon resistance to muscle traction [7, 26, 30, 35].

Recent animal studies on the role of bone marrow derived cells for the reconstruction of bone lesions have suggested that it can be safely explored in humans [16, 24]. Specifically, some studies have suggested a role for mononuclear cell therapy in osteonecrosis [23]. In addition, the use of bioactive glass associated with autologous bone marrow mononuclear cells (BMMC) has been successfully tested in benign bone lesions [29] and knee cartilage lesions [3, 10, 34].

The objective of the present study was to evaluate the possible advantages for tendon recovery of implanting autologous BMMC following transosseous suturing of the rotator cuff.

\section{Materials and methods}

This pilot study included 14 consecutive patients with rotator cuff injuries. Patients were diagnosed by clinical examination, conventional radiograph, and magnetic resonance imaging (MRI).

MRI was performed using a 1.5-T high-field scanner, closed bore (HD Excite, GE, Milwaukee, USA), in sagittal, coronal and axial planes, in T1- and T2-weighted fat-saturated sequences, in both the preoperative and postoperative evaluation of patients. This equipment was used because it was the high-field magnet device available at our institution. Readers evaluated tendon integrity, presence of complete retear, presence of abnormal areas of signal intensity at the tendon, myotendinous junction, muscle belly, tendon and muscle borders, bursal topography, and presence of abnormal artifacts.

Patients with a past history of rotator cuff injury repair, rheumatic or other connective tissue diseases, and patients involved in work compensation were excluded.

Prior to the orthopedic procedure, after general anesthesia, $100 \mathrm{ml}$ of bone marrow was obtained from the posterior iliac crest with the patient in lateral recumbent position. Bone marrow aspirates were transferred to the state cell therapy center. BMMC fractions were obtainedin aseptic conditions, according to Good Manufacturing Practices-by Ficoll-Hypaque density gradient and then resuspended in saline solution enriched with $10 \%$ autologous serum to a final volume of $10 \mathrm{ml}$. Final cell viability, as determined by trypan blue, was above $90 \%$. To confirm the bone marrow origin of the cells, an aliquot of the final suspension was submitted to flow cytometry analysis for the presence and counting of CD34, CD45 and CD38 cells in a 3-color FacsCalibur BD flow cytometer (BectonDickinson, San Jose, CA). The median concentration of CD34+ and mononuclear cells was $5.65 \times 10^{6}$ and $3.81 \times 10^{8}$, respectively.

During preparation of the mononuclear cell suspension, the patient was placed in the beach-chair position and surgery was initiated. Incision was performed using the transdeltoid lateral approach. All patients underwent acromioplasty for an increase in the subacromial space. Tendon-tendon and tendon-bone sutures were performed with Ethibond 5/0. After closure of the lesion, $10 \mathrm{ml}$ of the cell concentrate was injected in the tendon and bone participating in the "footprint". After closure, the patient was immobilized in a sling for 4 weeks. All patients were operated by the same surgeon with the same surgical technique. Physical therapy was initiated after the fourth week in a conventional rehabilitation protocol.

The following outcomes were assessed: functional status (UCLA score), tendon healing, and rate of rotator cuff retear.

All patients underwent functional evaluation both before and after surgery using UCLA scores [19]. This is an objective rating scale with adequate validity and reproducibility that assesses pain, function, range of motion, strength, and patient satisfaction. Pain and function may reach a maximum score of 10 , whereas other components may reach a maximum value of 5 . The overall score may reach 35 . Higher scores indicate better function of the shoulder.

This study was approved by the Research Ethics Committee (IRB-equivalent) of the appropriate institution. All patients provided informed consent.

\section{Results}

Of the 14 patients ( 9 women, 5 men, mean age of 59.2 years) with rotator cuff tears who entered the study, 5 had injuries to 3 tendons with fatty infiltration grade II or higher (Goutallier classification of fatty infiltration) [18], 8 patients had injuries to 2 tendons, with fatty infiltration grade II or higher in 5, and 1 patient had injury to 1 tendon. Mean preoperative UCLA score was 12 (standard deviation, 3.0; range, 7-16). After a minimum of 12-month follow-up period, the UCLA score increased to a mean 31 (standard deviation \pm 3.2 ; range, 26-35), which is considered to be a good score.

MRI analysis after a 12-month follow-up period demonstrated tendon integrity in all cases (14/14), presence of 
low signal intensity areas along the supraspinatus tendon and distal muscle belly in 8 cases (8/14), and high-intensity blooming small round artifact at the bursal and tendon topography in 11 cases (11/14). Six patients (6/14) showed formation of a high-signal intensity zone at the critical zone. None of these findings affected the final functional result (Fig. 1).

The time frame of 12 months was chosen because most papers in the literature mention the first year as the period during which the majority of the retears occur. Nevertheless, our findings remained stabilized at the end of the second postoperative year in all but one patient, who relapsed into pain and loss of strength, requiring a new surgical procedure.

\section{Discussion}

The most important findings of the present study were the positive results associated with implantation of mononuclear autologous stem cells following rotator cuff suturing. Our results showed that the procedure is safe and provides better functional outcomes than would usually be expected for such lesions. Many patients undergoing rotator cuff repair surgery show advanced degeneration of the tendons, which are thinner and atrophic, probably explaining why negative results are so often reported in the literature, with frequent postoperative complications, especially retear $[2,25]$. A number of researchers have shown, with either MRI or ultrasound, that tendon degeneration continues even after surgery [31]. Although tendon quality during suturing is essential for a successful treatment, this is one of the factors that we have not yet been able to change.

Despite all new technologies developed and incorporated into the surgical treatment of rotator cuff tears, there is no consistency in the literature with regard to outcomes of patients with large or massive injuries. According to several authors [4, 9, 14, 22, 28, 37], the $75 \%$ threshold of good results is not exceeded in this type of injury. Such failure is attributed not to technical limitations of the methods currently used, but to the poor quality of the treated tissue, i.e., rotator cuff tendons degenerated by intrinsic and extrinsic factors.

As both open surgery and arthroscopic surgery have exceeded the time required to overcome the learning curve, we cannot expect any changes to occur before the concepts and paradigms of conventional technology are changed. Therefore, the natural way to seek better results should necessarily shift its focus from tissue therapy to cell therapy [7, 26, 30, 35].

Over the last few years, the use of BMMC in the treatment of degenerative diseases has been extensively investigated. Studies have been conducted in cardiology [1], neurology [38], dentistry [32], and so forth. There are, however, few publications in the orthopedic field [2-5] addressing the use of BMMC in the recovery of tendons in rotator cuff tears.
Fig. 1 Preoperative coronal T2-weighted magnetic resonance image (MRI) showing complete injury with a 3 -cm retraction in 2 patients (a, b). Coronal T1-weighted (c) and T2-weighted (d) MRI sequences showing postoperative findings with tendons repaired, blooming artifacts at footprint, highintensity tissue at the footprint (c), and high-intensity tissue at tendon-bursa interface (d)
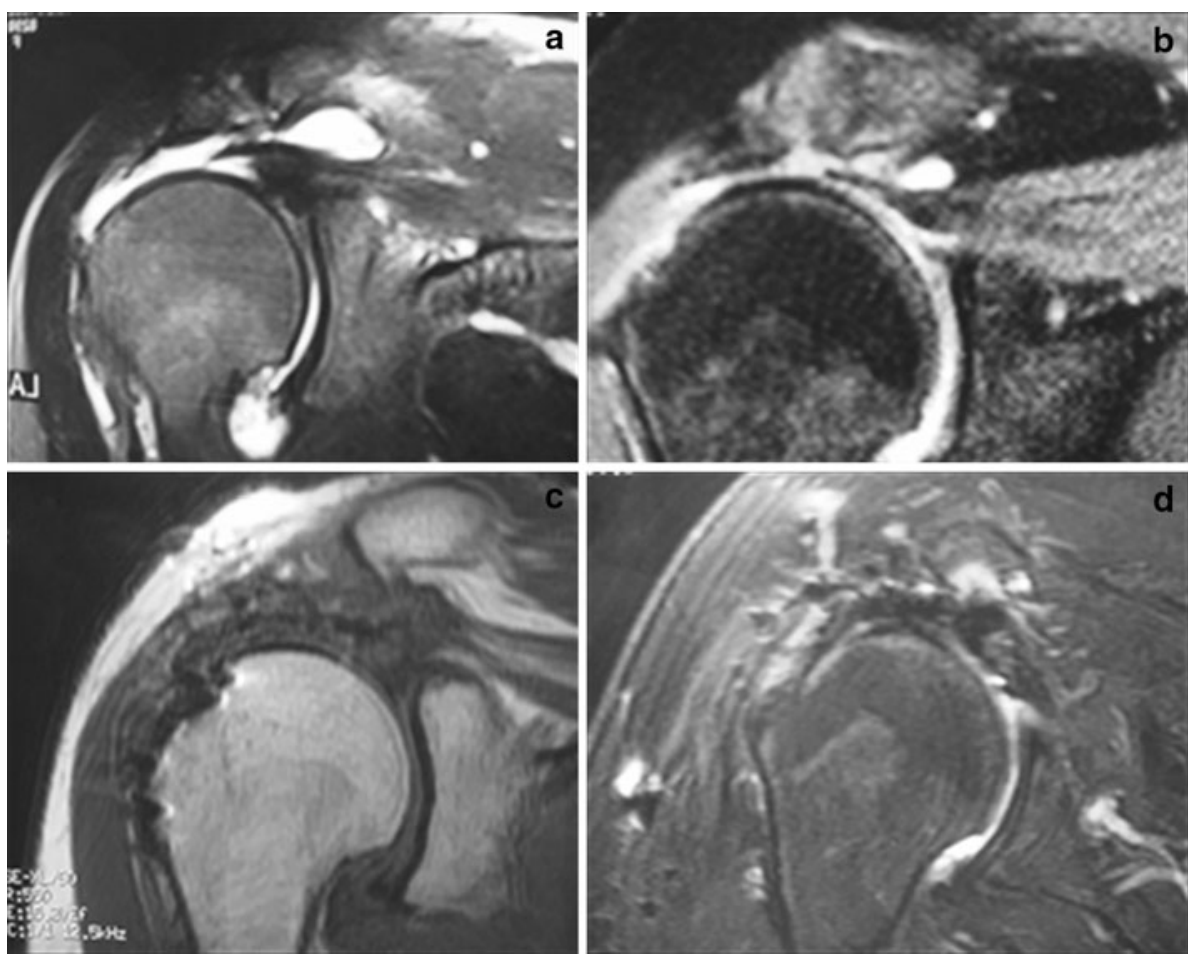
It has recently been suggested that, in addition to the skin, intestine and bone marrow, other tissues and organsliver, pancreas, skeletal muscle (associated with the locomotor system), adipose tissue and nervous system-have a stock of tissue-specific stem cells albeit with a limited capacity to regenerate after significant injury $[2,6]$. As for the muscle-skeletal system, in 1998, Ferrari et al. [12] were the first to describe the role of adult stem cells in tissue regeneration. The authors noted that genetically marked bone marrow cells injected into (chemically damaged) muscles of genetically immunodeficient mice were able to differentiate into muscle cells, thus reducing the injury. In another experiment, instead of injecting bone marrow cells directly into the muscle injury, immunodeficient mice received a bone marrow transplant [12]. Following transplantation, the authors found that the infused cells (genetically marked and therefore identifiable as belonging to the donor animal) migrated to the injured muscle area, suggesting that adult bone marrow stem cells are able to migrate to injured areas and differentiate into skeletal muscle cells. The aforementioned studies established two new important ideas: BMMC can give rise to skeletal muscle cells and can migrate to damaged areas in the muscle.

Other tendon diseases develop in a very similar way to rotator cuff injuries. Quadriceps and patellar tendinopathy, as well as epicondylitis (tennis elbow), behave similarly with respect to the development of tendon degeneration $[11,27]$. In these diseases, new treatments have gained ground trying to stimulate tendon regeneration, including shockwave therapy [13], microtenotomy, and thermal stimulation $[5,39]$. Their purpose is to cause "controlled damage" to the tendon in order to stimulate repair of the tendon structure via inflammatory reaction, i.e., recruitment of cells and angiogenesis. However, considering the replication and differentiation abilities of stem cells, one could assume that, if placed in a tissue such as a tendon, they could also stimulate its regeneration, similar to what is observed in other tissues. We decided to implant BMMC into the sick tendon, expecting to obtain greater stimulus for tendon tissue repair, by creating a healthier and more resilient set. When the use of BMMC was contemplated, there was no certainty about the results that could be obtained. However, the outcomes observed during postoperative functional and imaging assessment exceeded even the most optimistic expectations.

Conversely, a surprising finding was that some signal changes went beyond usual patterns of visualization of the tendons in MRI evaluation. The findings of areas of low signal in T1- and T2-weighted sequences at the supraspinatus distal belly and tendon borders called the readers' attention and were thought to correspond to hemosiderin accumulation, both because of the signal characteristics and because of the similarity with hemosiderin deposits in other entities, e.g., hemophilia and synovial pigmented vilonodular synovitis (PVNS). In turn, areas of T2 hyperintensity at the tendon's critical zone were thought to correspond to new tissue formation (regenerated tendon). It is, of course, not possible to specify the type of newly formed tissue, once we did not perform biopsy or histological analysis after surgery. Nevertheless, we can conclude that this newly formed tissue has some quality. Also, the presence of prominent blooming artifacts at the surgical site called the readers' attention and was thought to correspond to some kind of reaction of the tissue exposed to BMMC implantation. Although our study did not include controls and although our MRI analysis was based on subjective criteria, those 3 MRI findings really called readers attentions.

With regard to study limitations, it is necessary to point out that the procedures were not blind to patients and surgeon; therefore, the possibility of a biased result (Hawthorne effect) in the clinical and functional assessment cannot be ruled out. In addition, because cell therapy is frequently portrayed by the media as a redeeming treatment option, it is possible that such an environment, combined with unconscious stimulation on the part of evaluators, has influenced patients' opinions and therefore affected the quality of final results. Notwithstanding, the use of BMMC in tendon injuries may fill an important therapeutic gap that still exists today, despite all available technologies. Finally, although the initial results of this study have exceeded our expectations, further investigation into the topic, especially with larger samples, is yet to be conducted.

\section{Conclusion}

Patients undergoing sutures for rotator cuff tear associated with BMMC implantation in our sample presented promising results when compared with historical data available for patients undergoing the same surgical procedure without the addition of stem cells. Our preliminary results indicate that the procedure is safe and therefore reinforce the importance of further research to better investigate the use of this biological approach to enhance tissue quality in affected tendons.

Conflict of interest The authors declare that they have no conflicts of interest.

Open Access This article is distributed under the terms of the Creative Commons Attribution Noncommercial License which permits any noncommercial use, distribution, and reproduction in any medium, provided the original author(s) and source are credited. 


\section{References}

1. Barber FA, Coons DA, Ruiz-Suarez M (2007) Cyclic load testing of biodegradable suture anchors containing 2 high-strength sutures. Arthroscopy 23:355-360

2. Bigliani LU, Cordasco FA, McIlveen SJ, Musso ES (1992) Operative treatment of failed repairs of the rotator cuff. J Bone Joint Surg Am 74:1505-1515

3. Buda R, Vannini F, Cavallo M, Grigolo B, Cenacchi A, Giannini S (2010) Osteochondral lesions of the knee: a new one-step repair technique with bone-marrow-derived cells. J Bone Joint Surg Am 92(Suppl 2):2-11

4. Burkhart SS, Barth JR, Richards DP, Zlatkin MB, Larsen M (2007) Arthroscopic repair of massive rotator cuff tears with stage 3 and 4 fatty degeneration. Arthroscopy 23:347-354

5. Canquerini R, Gomes JE (2009) Radiofrequency microtenotomy for the treatment of chronic insertional tendinopathy: comparison of 2 surgical techniques and preliminary results. Tech Should Elb Surg 10:105-111

6. Caplan AI (2005) Review: mesenchymal stem cells: cell-based reconstructive therapy in orthopedics. Tissue Eng 11:1198-1211

7. Chang CH, Chen C, Su C, Liu H, Yu C (2009) Rotator cuff repair with periosteum for enhancing tendon-bone healing: a biomechanical and histological study in rabbits. Knee Surg Sports Traumatol Arthrosc 17:1447-1453

8. Codman EA (1990) Rupture of the supraspinatus tendon. 1911. Clin Orthop Relat Res 254:3-26

9. Cummins CA, Murrell GA (2003) Mode of failure for rotator cuff repair with suture anchors identified at revision surgery. J Should Elb Surg 12:128-133

10. de Girolamo L, Bertolini G, Cervellin M, Sozzi G, Volpi P (2010) Treatment of chondral defects of the knee with one step matrixassisted technique enhanced by autologous concentrated bone marrow: in vitro characterisation of mesenchymal stem cells from iliac crest and subchondral bone. Injury 41:1172-1177

11. Eriksson E (2002) Tendinosis of the patellar and achilles tendon. Knee Surg Sports Traumatol Arthrosc 10:1

12. Ferrari G, Cusella-De Angelis G, Coletta M, Paolucci E, Stornaiuolo A, Cossu G, Mavilio F (1998) Muscle regeneration by bone marrowderived myogenic progenitors. Science 279:1528-1530

13. Fridman R, Cain JD, Weil L Jr, Weil L Sr (2008) Extracorporeal shockwave therapy for the treatment of Achilles tendinopathies: a prospective study. J Am Podiatric Med Assoc 98:466-468

14. Galatz LM, Ball CM, Teefey SA, Middleton WD, Yamaguchi K (2004) The outcome and repair integrity of completely arthroscopically repaired large and massive rotator cuff tears. J Bone Joint Surg Am 86-A:219-224

15. Gerber C, Fuchs B, Hodler J (2000) The results of repair of massive tears of the rotator cuff. J Bone Joint Surg Am 82:505-515

16. Geuze RE, Kruyt MC, Verbout AJ, Alblas J, Dhert WJ (2008) Comparing various off-the-shelf methods for bone tissue engineering in a large-animal ectopic implantation model: bone marrow, allogeneic bone marrow stromal cells, and platelet gel. Tissue Eng Part A 14:1435-1443

17. Goble EM, Somers WK, Clark R, Olsen RE (1994) The development of suture anchors for use in soft tissue fixation to bone. Am J Sports Med 22:236-239

18. Goutallier D, Bernageau J, Patte D (1989) L'évaluation par le scanner de la trophicité des muscles de la coiffe des rotateurs ayant une rupture tendineuse. Rev Chir Orthop Reparatrice Appar Mot 75(suppl 1):126-127

19. Harvie P, Pollard TC, Chennagiri RJ, Carr AJ (2005) The use of outcome scores in surgery of the shoulder. J Bone Joint Surg Br $87: 151-154$
20. Hoffmann A, Gross G (2006) Tendon and ligament engineering: from cell biology to in vivo application. Regen Med 1:563-574

21. James R, Kesturu G, Balian G, Chhabra AB (2008) Tendon: biology, biomechanics, repair, growth factors, and evolving treatment options. J Hand Surg Am 33:102-112

22. Jones CK, Savoie FH 3rd (2003) Arthroscopic repair of large and massive rotator cuff tears. Arthroscopy 19:564-571

23. Jones KB, Seshadri T, Krantz R, Keating A, Ferguson PC (2008) Cell-based therapies for osteonecrosis of the femoral head. Biol Blood Marrow Transplant 14:1081-1087

24. Karaoglu S, Celik C, Korkusuz P (2009) The effects of bone marrow or periosteum on tendon-to-bone tunnel healing in a rabbit model. Knee Surg Sports Traumatol Arthrosc 17:170-178

25. Karas EH, Iannotti JP (1998) Failed repair of the rotator cuff: evaluation and treatment of complications. Instr Course Lect 47:87-95

26. Kovacevic D, Rodeo S (2008) Biological augmentation of rotator cuff tendon repair. Clin Orthop Relat Res 466:622-633

27. Kraushaar BS, Nirschl RP (1999) Tendinosis of the elbow (tennis elbow). Clinical features and findings of histological, immunohistochemical, and electron microscopy studies. J Bone Joint Surg Am 81:259-278

28. Lam F, Mok D (2004) Open repair of massive rotator cuff tears in patients aged sixty-five years or over: is it worthwhile? J Should Elb Surg 13:517-521

29. Liu H, Sun J, Wang Y, Yang X, Zhu E (2008) Repairing bone defects of benign bone neoplasm by grafting of bioactive glass combined with autologous bone marrow. Zhongguo Xiu Fu Chong Jian Wai Ke Za Zhi 22:1349-1353

30. Maniscalo P, Gambera D, Lunati A, Vox G, Fossombroni V, Beretta R, Crainz E (2008) The cascade membrane: a new PRP device for tendon ruptures. Description and case report on rotator cuff tendon. Acta Biomed (Italy) 79:223-236

31. Mellado JM, Calmet J, Olona M, Esteve C, Camins A, Perez Del Palomar L, Gine J, Sauri A (2005) Surgically repaired massive rotator cuff tears: MRI of tendon integrity, muscle fatty degeneration, and muscle atrophy correlated with intraoperative and clinical findings. AJR Am J Roentgenol 184:1456-1463

32. Morsczeck C, Schmalz G, Reichert TE, Vollner F, Galler K, Driemel O (2008) Somatic stem cells for regenerative dentistry. Clin Oral Investig 12:113-118

33. Neer CS 2nd (1972) Anterior acromioplasty for the chronic impingement syndrome in the shoulder: a preliminary report. J Bone Joint Surg Am 54:41-50

34. Nejadnik H, Hui JH, Feng Choong EP, Tai BC, Lee EH (2010) Autologous bone marrow-derived mesenchymal stem cells versus autologous chondrocyte implantation: an observational cohort study. Am J Sports Med 38:1110-1116

35. Randelli PS, Arrigoni P, Cabitiza P, Volpi P, Maffulli N (2008) Autologous platelet rich plasma for arthroscopic rotator cuff repair. A pilot study. Disabil Rehabil (England) 30:1584-1589

36. Riley GP, Harrall RL, Constant CR, Chard MD, Cawston TE, Hazleman BL (1994) Tendon degeneration and chronic shoulder pain: changes in the collagen composition of the human rotator cuff tendons in rotator cuff tendinitis. Ann Rheum Dis 53:359-366

37. Rokito AS, Cuomo F, Gallagher MA, Zuckerman JD (1999) Long-term functional outcome of repair of large and massive chronic tears of the rotator cuff. J Bone Joint Surg Am 81:991-997

38. Sasaki M, Radtke C, Tan AM, Zhao P, Hamada H, Houkin K, Honmou O, Kocsis JD (2009) BDNF-hypersecreting human mesenchymal stem cells promote functional recovery, axonal sprouting, and protection of corticospinal neurons after spinal cord injury. J Neurosci 29:14932-14941

39. Tasto JP, Cummings J, Medlock V, Hardesty R, Amiel D (2005) Microtenotomy using a radiofrequency probe to treat lateral epicondylitis. Arthroscopy 21:851-860 